\title{
GhMPK16, a novel stress-responsive group D MAPK gene from cotton, is involved in disease resistance and drought sensitivity
}

\author{
Jing Shi, Liang Zhang, Hailong An, Changai Wu and Xingqi Guo*
}

\begin{abstract}
Background: Mitogen-activated protein kinase (MAPK) cascades play pivotal roles in mediating biotic and abiotic stress responses. In plants, MAPKs are classified into four major groups (A-D) according to their sequence homology and conserved phosphorylation motifs. Members of group A and B have been extensively characterized, but little information on the group D MAPKs has been reported.

Results: In this study, we isolated and characterised GhMPK16, the first group D MAPK gene found in cotton. Southern blot analysis suggests GhMPK16 is single copy in the cotton genome, and RNA blot analysis indicates that GhMPK16 transcripts accumulate following pathogen infection and treatment with multiple defense-related signal molecules. The analysis of the promoter region of GhMPK16 revealed a group of putative cis-acting elements related to stress responses. Subcellular localization analysis suggests that GhMPK16 acts in the nucleus. Transgenic Arabidopsis overexpressing GhMPK16 displayed significant resistance to fungi (Colletotrichum nicotianae and Alternaria alternata) and bacteria (Pseudomonas solanacearum) pathogen, and the transcripts of pathogen-related (PR) genes were more rapidly and strongly induced in the transgenic plants. Furthermore, transgenic Arabidopsis showed reduced drought tolerance and rapid $\mathrm{H}_{2} \mathrm{O}_{2}$ accumulation.

Conclusion: These results suggest that GhMPK16 might be involved in multiple signal transduction pathways, including biotic and abiotic stress signaling pathways.
\end{abstract}

Keywords: Cotton (Gossypium hirsutum) GhMPK16, Pathogen resistance, Drought sensitivity

\section{Background}

Stresses such as drought, high salinity and fungal infections constitute a major limitation to crop productivity. Plants have developed sophisticated defense mechanisms to deal with diverse unfavorable environmental factors. The mitogen-activated protein kinase (MAPK) cascades are conserved pathways through which extracellular stimuli are transduced into intracellular responses in all eukaryotes [1,2]. Plant MAPK cascades have been shown to regulate a number of essential biological processes, including growth, development and stress responses [3].

MAPK cascades are composed of three interlinked protein kinases: MAPKK kinases (MAPKKKs or

\footnotetext{
* Correspondence: cawu@sdau.edu.cn; xqguo@sdau.edu.cn

State Key Laboratory of Crop Biology, Shandong Key Laboratory of Crop Biology, Shandong Agricultural University, Taian, Shandong 271018, China
}

MAP3Ks), MAPK kinases (MAPKKs, MAP2Ks or MEKs) and MAPKs. MAPKs are the terminal components in this cascade, and they are regulated by the dual phosphorylation of the conserved T-X-Y motif located in the activation loop by upstream kinases (MAPKKs). There are 20 MAPK genes identified in Arabidopsis, and a similar repertoire of genes have been found in other plants, such as rice (Oryza sativa), poplar (Populus sp.) and grapevine (Vitis vinifera) [3-5]. The MAPKs can be categorised into four major groups (A, B, C, and D) based on the phylogenetic analyzes of amino acid sequences and phosphorylation motifs (TEY and TDY). The TEY subtype can be classified into three groups (A, $B$ and $C$ ), whereas the TDY subtype is found in the more distant group D [4,5].

In Arabidopsis, three particular MAPKs in groups A and B (MPK3, MPK4 and MPK6) have been extensively

\section{() Biomed Central}

(c) 2011 Shi et al; licensee BioMed Central Ltd. This is an Open Access article distributed under the terms of the Creative Commons Attribution License (http://creativecommons.org/licenses/by/2.0), which permits unrestricted use, distribution, and reproduction in any medium, provided the original work is properly cited. 
studied. Both biochemical and genetic analyzes have been performed for each of these isoforms, which appear to work in multiple signaling pathways and play crucial roles in many distinct processes ranging from stress responses to developmental processes [3]. Information about group $\mathrm{C}$ MAPKs has recently emerged. Three members of group C, MPK1 and MPK2 in Arabidopsis and PSMPK2 in pea (Pisum sativum L.), are transcriptionally induced by a variety of stresses [6,7]. More recently, Arabidopsis group C MAPKs, including MPK1, MPK2, MPK7 and MPK14, were reported to be activated by MKK3, and MKK3-MPK7 participates in pathogen signaling [8]. Cotton GhMPK7 may play a role in pathogen resistance, plant growth and development [9].

Based on the phylogenetic analysis and pairwise comparison of Arabidopsis and rice MAPKs, it has been proposed that the rice genome contains more MAPKs with a TDY phosphorylation motif (11 members) than with a TEY motif (6 members). In contrast, the Arabidopsis genome contains more MAPKs with a TEY motif (12 members) than with a TDY motif (8 members) [10]. Detailed functional data about TDY MAPKs was first obtained from a monocot plant. Overexpression of OsBWMK1 (also known as OsMPK12) in tobacco resulted in constitutive $\mathrm{PR}$ gene expression and enhanced resistance to fungal and bacterial infections [11]. In maize, ZmMPK6 is able to interact with a 14-33 protein, and these data represent the first evidence of the possible involvement of 14-3-3 proteins in the regulation of MAPK cascades in plants [12]. More recently, Arabidopsis MPK9 (a group D MAPK) and MPK12 (a group B MAPK) were found to be preferentially expressed in guard cells, share functional redundancy and function as positive regulators downstream of reactive oxygen species (ROS) in guard cell abscisic acid (ABA) signaling [13]. Moreover, Arabidopsis MPK18 helps to mediate cortical microtubule functions in plant cells [14].

Cotton (Gossypium hirsutum) is one of the most important fibre and oil crops, and its growth and yield are severely impaired in various biotic/abiotic stress conditions. The biological significance of cotton group D MAPKs has not yet been described. In this study, a cDNA clone, GhMPK16, encoding a putative group D MAPK gene was isolated and characterised. Our results indicate that the expression of GhMPK16 is induced by chemical and biological signals. Ectopic expression of GhMPK16 in Arabidopsis results in enhanced disease resistance against fungi and bacteria pathogen. Moreover, GhMPK16 transgenic plants were obviously more drought-sensitive than control plants. We deduced that GhMPK16 may play important roles in regulating pathogen resistance and drought signaling.

\section{Results}

Cloning and characterisation of the full-length GhMPK16 cDNA

Based on the conserved region of plant group D MAPK genes, the degenerate primers MP1 and MP2 were designed and synthesized to clone the internal conserved region of MAPKs from cotton, and a putative MAPK fragment (476 bp) was cloned. Next, rapid amplification of CDNA ends-PCR (RACE-PCR) was performed, and the full length sequence was retrieved. A 3 '-end fragment of about $1500 \mathrm{bp}$ and a 5 '-end fragment of about $360 \mathrm{bp}$ were obtained with the specific primers. The full-length cDNA sequence was PCR amplified using the gene-specific primers (FL1 and FL2), and it showed a high degree of homology to group D MAPKs especially Arabidopsis AtMPK16. According to the nomenclature for plant MAPKs, the novel cotton $M A P K$ gene was named GhMPK16 [4,5], and is the first group $\mathrm{D}$ MAPK identified in cotton. The full-length cDNA sequence of GhMPK16 (GenBank accession number: FJ966889) was 2030 bp with a 78 bp 5' untranslated region (UTR) and a 287 bp 3' UTR. The cDNA contains a 1665 bp open reading frame (ORF) that is predicted to encode a protein of 554 amino acids with a predicted molecular mass of $63.18 \mathrm{kDa}$ and an isoelectric point (pI) of 8.61.

A BLAST search (http://www.ncbi.nlm.nih.gov/ BLAST) and multi-alignment analysis revealed that GhMPK16 is highly related to other group D MAPKs, sharing a homology of $81.48 \%$ to AtMPK16, $72.18 \%$ to TaMAPK2, $74.56 \%$ to OsMPK16-1 and $76.02 \%$ to ZmMPK6 (Figure 1A). Moreover, as with other known plant group D MAPKs, GhMPK16 has the same family signature of 11 conserved subdomains, an activation loop (T-loop), a phosphorylation motif (TDY motif) in the $\mathrm{T}$-loop, and an extended $\mathrm{C}$-terminal region relative to groups A, B and C. Additionally, GhMPK16 also lacks a $C$-terminal $C D$ domain, a feature conserved in MAPKs belonging to the other groups (A, B, C) [4].

To reveal the evolutionary relationship of GhMPK16 with other MAPKs from various plant species, we constructed a phylogenetic tree using amino acid sequences derived from the GenBank database (Figure 1B). Our results indicate that GhMPK16 has high similarity with AtMPK16 and a close genetic relationship with many monocot (rice, corn, and wheat) group D MAPKs, such as OsMPK16-1, OsMPK15, ZmMPK6 and TaMAPK2, which suggests that these genes may have a similar function across species including dicotyledons and monocotyledons.

\section{Genomic structure and Southern blot analysis of GhMPK16}

To isolate a genomic GhMPK16 clone, two pairs of specific primers, FL1/Z1 and FL2/Z2, were designed 


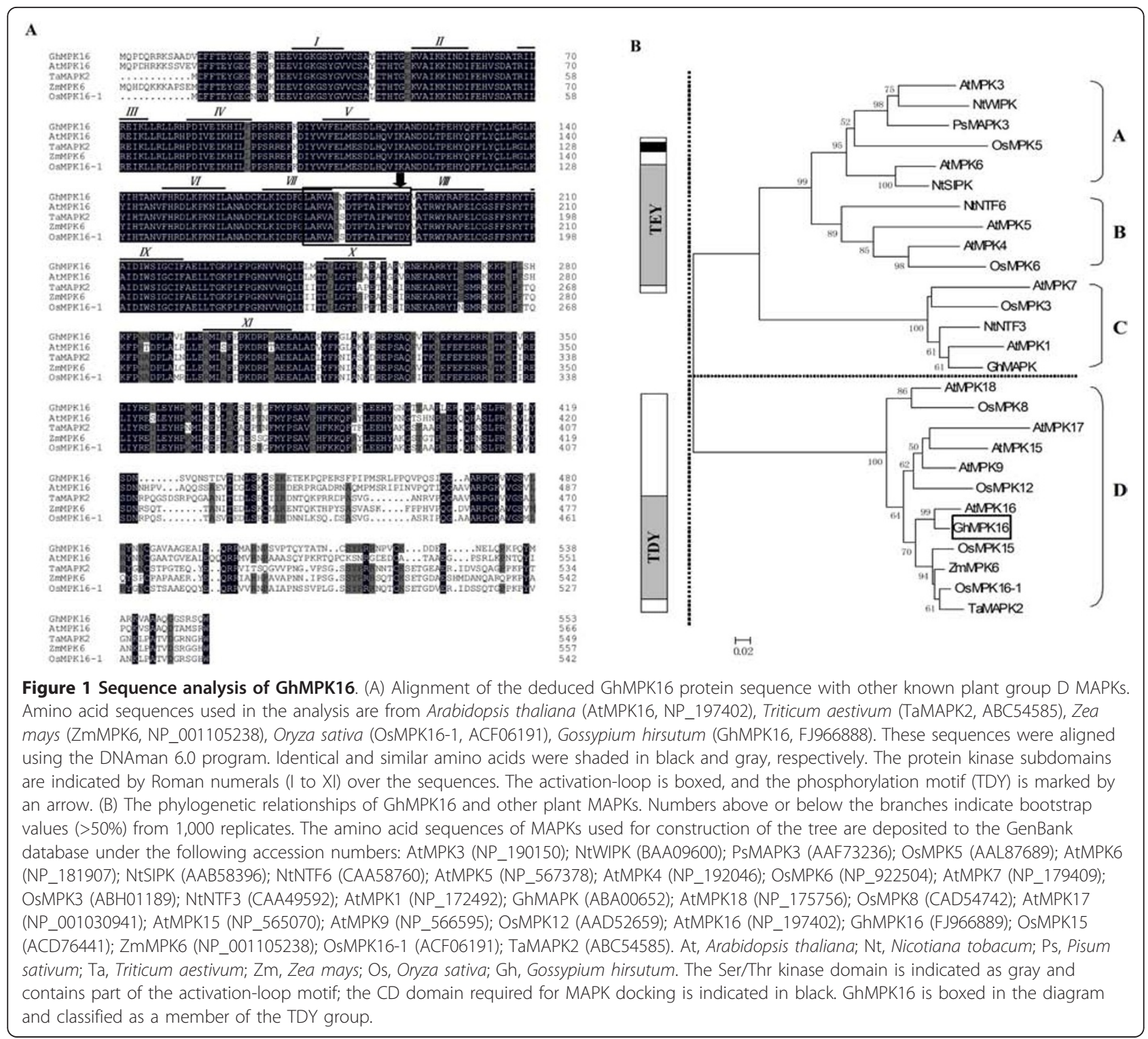

based on the GhMPK16 cDNA sequence, and the cotton genomic DNA was used as the template to generate two PCR fragments. These two fragments were further linked together through their overlapping region and the full-length GhMPK16 genomic sequence of 5520 bp (GenBank accession number: FJ966896) was deduced. A comparison between the GhMPK16 genomic and cDNA sequences indicated that ten introns were present in the gene (Additional file 1: supplementary Figure S1). Interestingly, exon 8 was only $5 \mathrm{bp}$, intron 7 did not contain a 3'-splice acceptor AG signal, and intron 8 did not contain the conserved 5'-splice donor GT signal. A comparative analysis of the homologous genes from Arabidopsis thaliana, Oryza sativa and Vitis vinifera was performed (Additional file 1: supplementary Figure S1).
This analysis indicated that the size of the exons was conserved, but the length of the introns for each member was different. To date, the most noticeable difference in GhMPK16 was the number of exons. GhMPK16 has 11 exons, and the others have 10.

Southern blots were used to investigate the genomic organization of the GhMPK16 gene. Genomic DNA was completely digested with EcoR V, Xba I, Hind III and $E c o$ R I and hybridised to the 3' partial sequence of GhMPK16, which contains no restriction sites of EcoR V, Hind III and EcoR I and only one Xba I site presents in the probe region. As shown in Figure 2, only one band was observed for the EcoR V, Hind III and EcoR I digestions, and two bands were observed for the $\mathrm{Xba} \mathrm{I}$ digestion. These results imply that there is a single GhMPK16 gene in the cotton genome. 


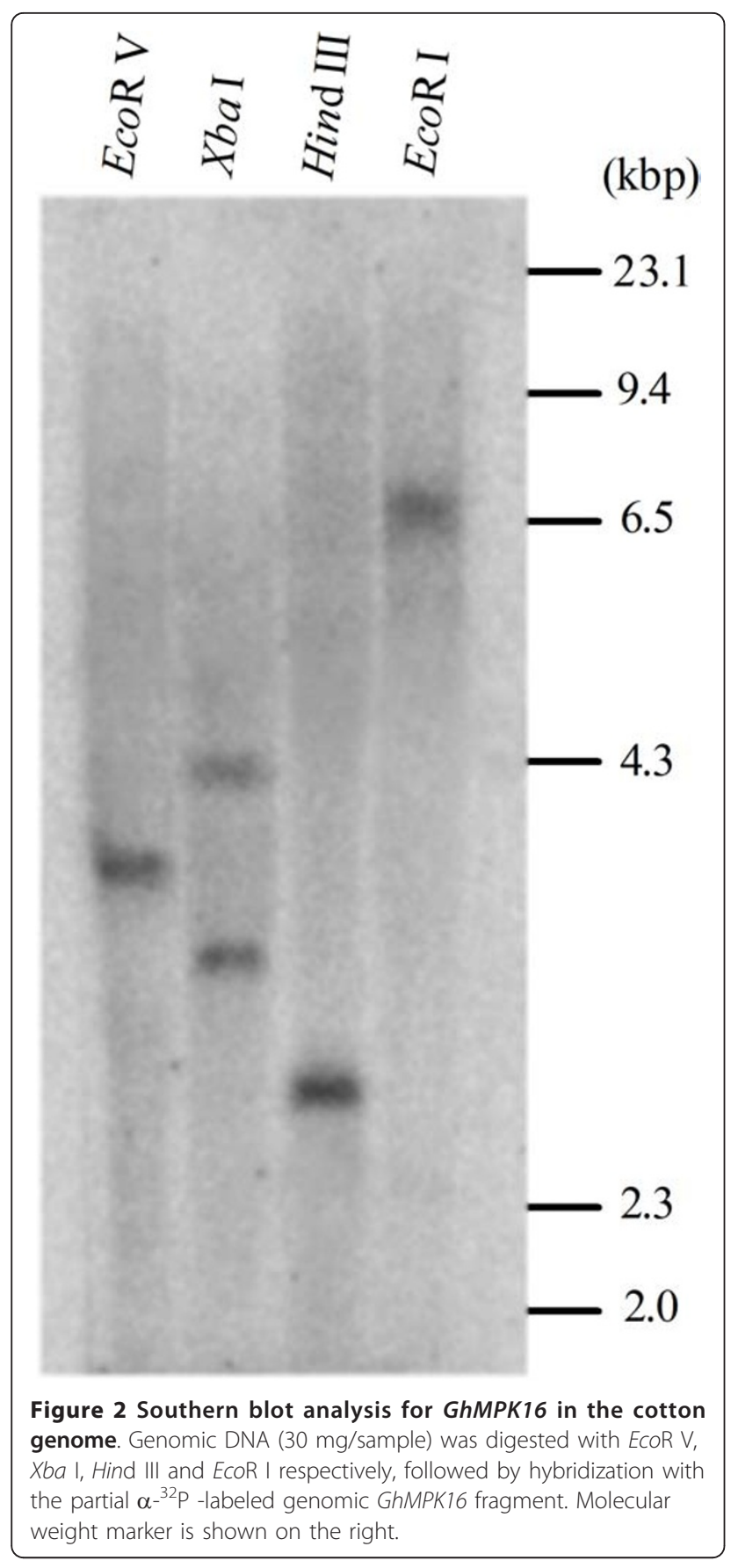

\section{Subcellular localization of GhMPK16}

To reveal the cellular localization of GhMPK16, a reporter gene encoding GFP was fused to GhMPK16 and placed under the control of the CaMV35S promoter, and immunoblot analysis indicated that GhMPK16::GFP was an integrated fusion protein (Additional file 2: supplementary Figure S2). The biolistic transformation system was used for a transient assay in onion epidermal cells. The nuclear localization of GFP-conjugated GhMPK16 was confirmed in individual transgenic cells by GFP fluorescence, using DAPI staining to detect the nuclei and interference contrast images to detect wholecell structures. As shown in Figure 3B, the $35 \mathrm{~S}$ GhMPK16::GFP construct localized to the nucleus, and the 35S-GFP control construct showed GFP signals in both the cytoplasm and the nucleus. In addition, a program that predicts the subcellular localization of proteins (http://www.bioinfo.tsinghua.edu.cn/SubLoc/) predicted that GhMPK16 is localized in the nucleus with an expected accuracy of nearly $74 \%$. These results indicate that the GhMPK16 protein is likely localized in the nucleus.

\section{Expression pattern of GhMPK16 under diverse abiotic and biotic stresses in cotton}

To determine whether GhMPK16 expression is triggered by abiotic stresses, cotton seedlings were exposed to low and high temperatures, mannitol, $\mathrm{NaCl}$ and wounding treatments. GhMPK16 showed a slightly response to low and high temperatures (Figure 4A, B, C). GhMPK16 transcripts accumulated within $6 \mathrm{~h}$ following mannitol treatment, and the induction was still present $12 \mathrm{~h}$ after treatment (Figure 4D). As shown in Figure 4E, GhMPK16 expression increased and reached the maximum at $8 \mathrm{~h}$ after the $\mathrm{NaCl}$ treatment. Wounding rapidly and transiently enhanced the expression level of GhMPK16 (Figure $4 \mathrm{~F})$. Taken together, the expression profiles indicate that GhMPK16 is induced by various abiotic stresses.

To explore the roles of GhMPK16 in plant biotic stresses, cotton seedlings were inoculated with pathogens, including Xanthomonas campestris pv. malvacearum (X. campestris pv. malvacearum), Colletotrichum gossypii (C. gossypii) and Fusarium oxysporum f. sp. vasinfectum (F. oxysporum f. sp. vasinfectum). As shown in Figure 4 (G, H, I), infection by all of these pathogens elevated the transcription level of GhMPK16, although the induction kinetic was variable. There was no significant change in GhMPK16 transcript level without pathogen treatment during 7 days (Figure 4J). These results indicate that GhMPK16 may be intimately involved in the plant pathogen defense response.

Additionally, we examined the response of GhMPK16 to exogenously applied salicylic acid (SA), methyl jasmonate (MeJA) and ABA, which are plant signaling molecules involved in plant defense signaling pathways. The expression of GhMPK16 was induced by all of these signal molecules (Figure 4K, L, M). Furthermore, the solvent control (Ethanol) did not significantly induce the expression of GhMPK16 (Figure 4N)

\section{GhMPK16 promoter analysis}

Inverse-PCR (I-PCR) was used to obtain a $785 \mathrm{bp}$ fragment of the 5' flanking region upstream of the transcriptional start site, as determined by the GhMPK16 cDNA 


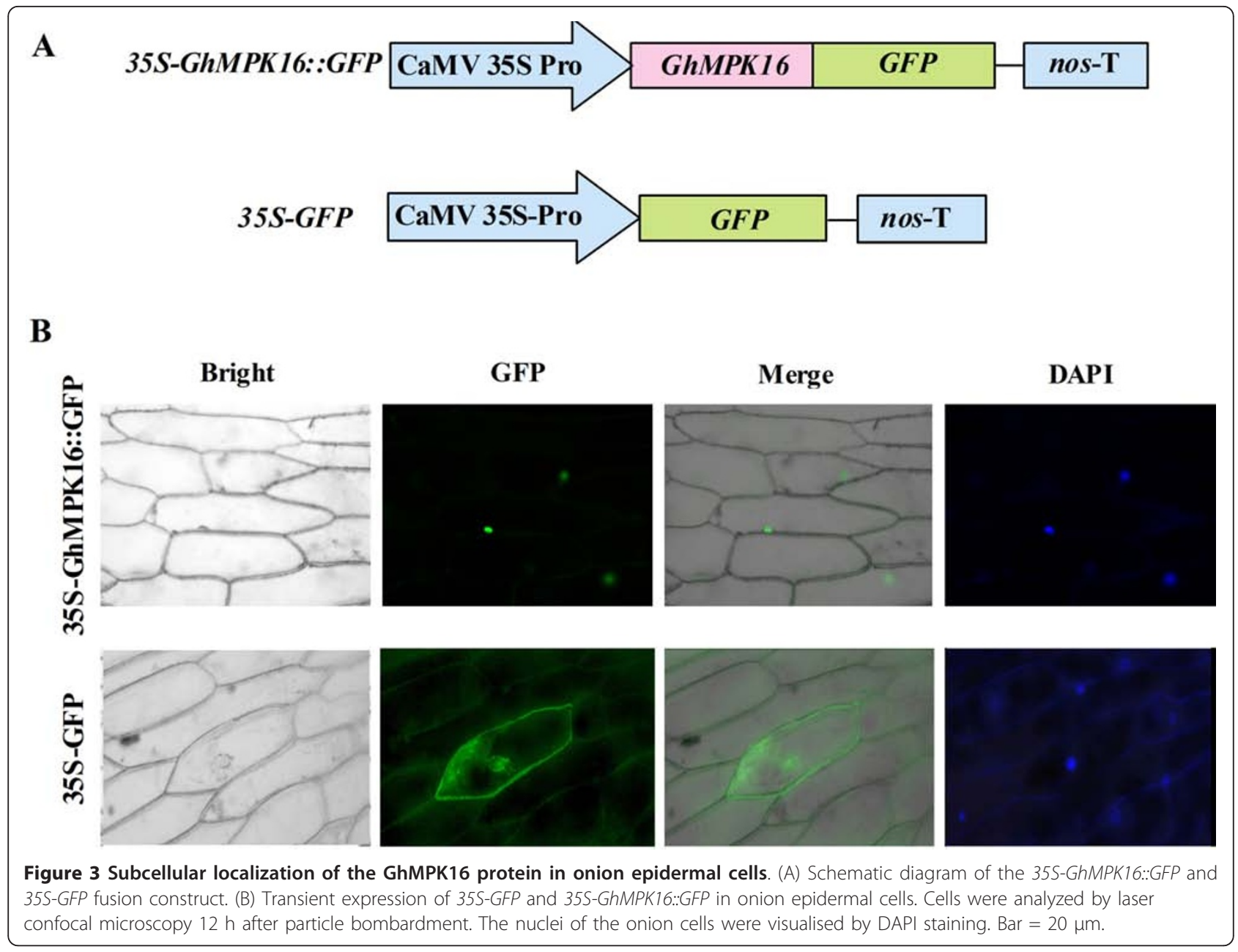

sequence. In order to find cis-acting elements, the PlantCARE databases were analyzed. Sequence analysis revealed that the GhMPK16 promoter contains TATA and CAAT motifs located at nucleotides -38 and -64 relative to the transcriptional start site, respectively, which is characteristic of eukaryotic gene promoters. As shown in Figure 5, the 785 bp promoter region contains several motifs probably related to pathogen and drought signals, such as a Box-W1 element (fungal elicitor responsive element), an ERE element (ethylene-responsive element), two TCA-element (cis-acting SA-responsive element) and a MBS element (MYB binding site involved in drought-inducibility). This suggests that these putative cis-acting elements are responsible for enhanced expression of GhMPK16 during stress conditions.

\section{Enhanced resistance of GhMPK16 transgenic plants to pathogenic infections}

In order to further explore the function of GhMPK16 in plant defense, the coding sequence of GhMPK16 was cloned into the plant binary vector pBI121 and transformed into Arabidopsis. A total of 32 independent transgenic lines were obtained by kanamycin-resistance selection and confirmed by PCR (data not shown). RNA blot analysis was performed to determine the transgenic expression levels in 7 randomly selected lines (Figure 6A). Two representative lines (\#2 and \#5) exhibiting different expression levels were selected and their $T_{3}$ transgenic plants used to evaluate disease resistance.

To analyze bacterial resistance responses in wild-type and GhMPK16-overexpressing plants, 3-week-old plants were inoculated with $P$. solanacearum and monitored daily for the appearance of typical disease symptoms. $P$. solanacearum caused more severe chlorotic symptoms in the wild-type plants compared to the transgenic plants $6 \mathrm{~d}$ after inoculation (Figure 6B). As shown in Figure $6 \mathrm{C}$, the bacterial titres in the inoculated leaves of the transgenic plants were significantly reduced as compared to those in wild-type plants at 3- and 6-day postinoculation, which is consistent with the observed symptoms. The rate of bacterial growth in the inoculated 
A

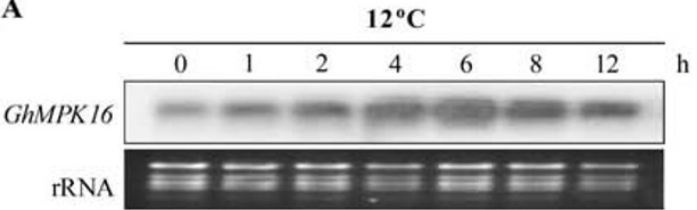

C

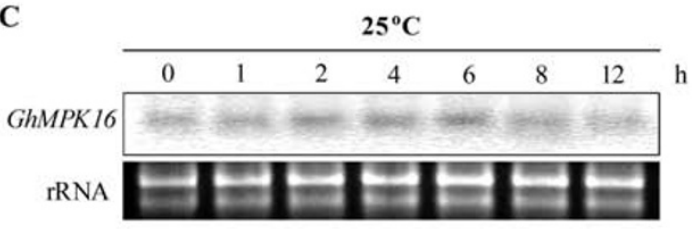

E

$\mathbf{E}$

GhMPK 16

rRNA

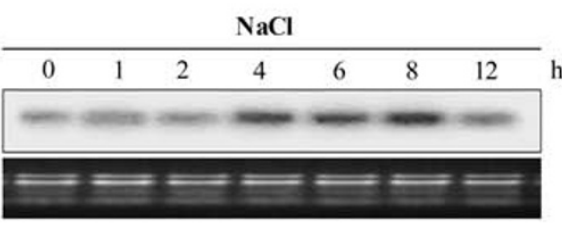

G

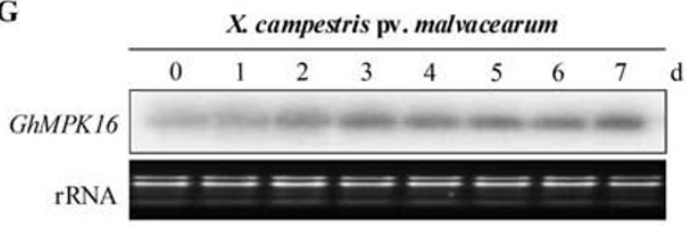

I

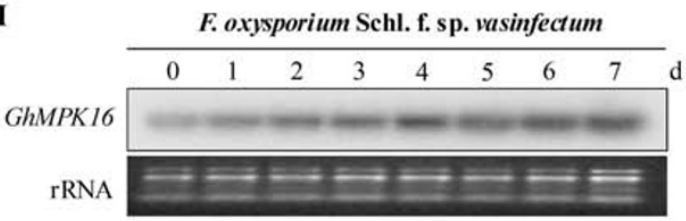

K

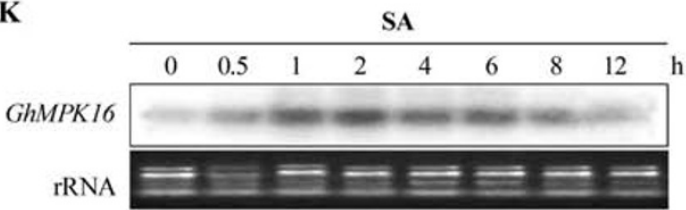

M

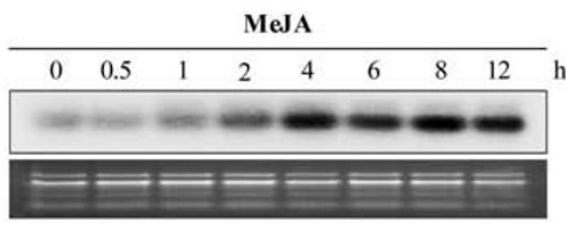

B

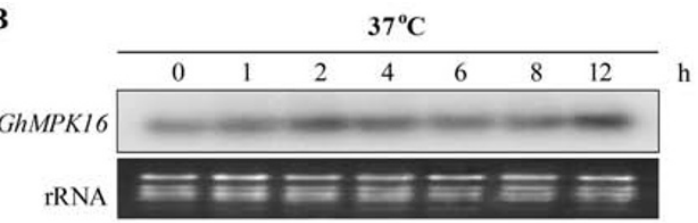

D

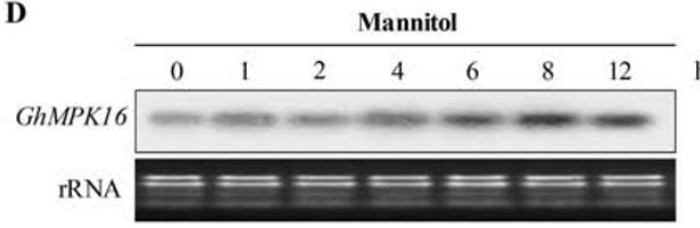

F

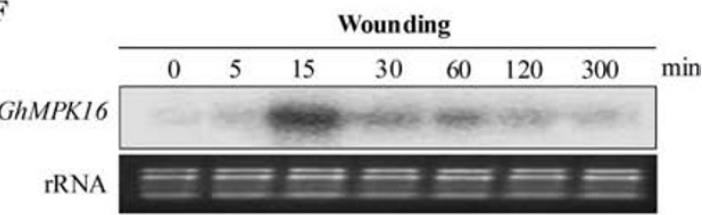

H

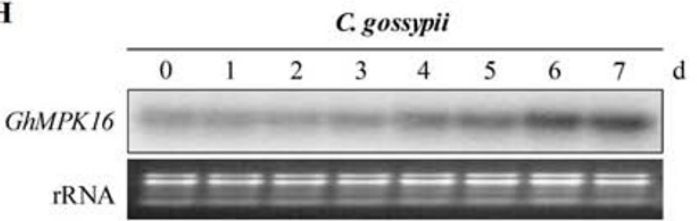

$\mathbf{J}$

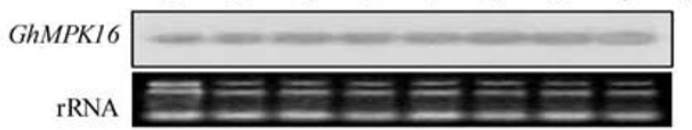

$\mathbf{L}$

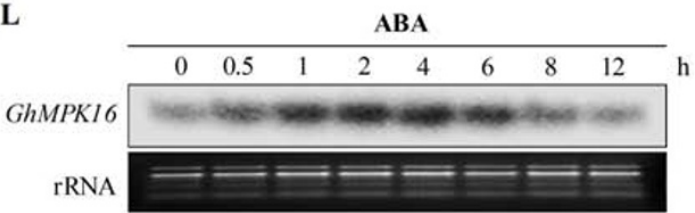

$\mathbf{N}$

\begin{tabular}{|c|c|c|c|c|c|c|c|}
\hline \multicolumn{8}{|c|}{ Ethanol } \\
\hline 0 & 0.5 & 1 & 2 & 4 & 6 & 8 & 12 \\
\hline \multicolumn{8}{|c|}{ 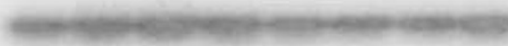 } \\
\hline E & $\underline{\underline{E}}$ & $=$ & $=$ & $=$ & $=$ & & $=$ \\
\hline
\end{tabular}

Figure 4 Expression profiles of GhMPK16 under abiotic/biotic stresses. RNA blots were performed with total RNA extracted from leaves at the indicated times, and treated with low temperature $\left(12^{\circ} \mathrm{C}\right)(\mathrm{A})$, high temperature $\left(37^{\circ} \mathrm{C}\right)(\mathrm{B})$, normal temperature $\left(25^{\circ} \mathrm{C}\right)(\mathrm{C}), 200 \mathrm{mM}$ mannitol (D), $200 \mathrm{mM} \mathrm{NaCl}(\mathrm{E})$, wounding (F), X. campestris pv. Malvacearum (G), C. gossypii (H), F. oxysporum f. sp. Vasinfectum (I), mock (J), $10 \mathrm{mM} \mathrm{SA} \mathrm{(K),}$ $100 \mu \mathrm{M}$ ABA (L), $100 \mu \mathrm{M}$ MeJA (M), or ethanol (N). Ethidium bromide-stained rRNA was used as the loading control. 


\begin{tabular}{|c|c|}
\hline & ERE $\rightarrow$ \\
\hline-785 & 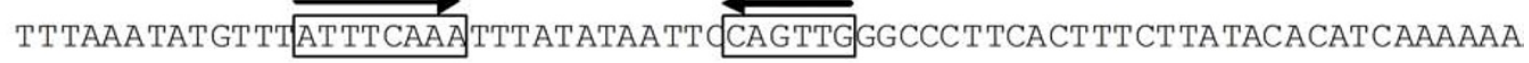 \\
\hline-715 & $\begin{array}{l}\text { AAAAAAGAAAGAAAGAAAGAAAGAAAGAAAAAGCC TTCAACTTGAAGCACAGCACTCTTTGATTTCCACT } \\
\text { TCA-element }\end{array}$ \\
\hline-645 & 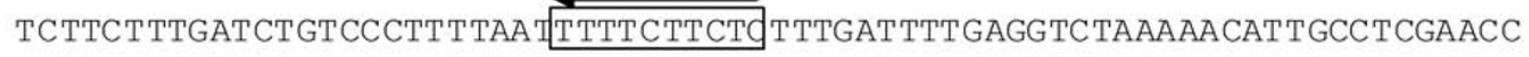 \\
\hline-575 & $\begin{array}{l}\text { CAAACCCCCCC TTTTTTTTCCACTCCCAAAAAACAAAATAAGAAAAAAAATCCAAACTT TATCTATCTTC } \\
\text { TCA-element }\end{array}$ \\
\hline-505 & TATAATATTTATAAATTAATTATT TTTTTCTTGTT TTTATTGTGTTTTTATAGTGT TAATCGCCTGGTAT \\
\hline-435 & AGATTCTTCTCCAAGTGACTCTCATTTTCTAGCTCAATTTGTTTTTTAGGCTCATCTGCCACAAAGCCAA \\
\hline-365 & САTCTTTTGGCCTTATAGTGTTTCTTGCCTTTGAAAAAAAAAAAACAATCAAAGATTTTTTTTCATTTTT \\
\hline-295 & TTCTTCTATGTTATTAGTTAAAAGTTGTTAACTTTATCCTCAAAATCTTGAAGTAGCTGAATATTGAGTG \\
\hline-225 & TTGTTTGAACTTGGAACTTTTGCTCTCAAGCTATTTCTTTGGGCGATTTTTGGTAAGGCTGTTTTGATTG \\
\hline-155 & TTGATCTTGATGCTTTTTTGGTTAATTTTT TCCCT TTTTGAACTGTTCTGAAATCTGGGTATTTTTTTT \\
\hline & $\begin{array}{cl}\text { CAAT-box } & \text { Box-W/ } \\
\text { TATA-box }\end{array}$ \\
\hline-85 & $\begin{array}{c}\text { TTGGTTTTTTCTAGGAATTTGGTC TTGGCATTAdTTGACdTTTAATATTTTGTGATCTT TTGATTTGGGT } \\
+1\end{array}$ \\
\hline-15 & TTTAACTGCAAAGTGAACTTGGTT TCTACTATTAC TTTGGGGGCTTCCTGTT TGAT GCCAATTGTTT TCT \\
\hline 56 & GTTTCCAAAGTTTTGATGCTAAGATG* \\
\hline \multicolumn{2}{|r|}{$\begin{array}{l}\text { Figure } 5 \text { Nucleotide sequence of the promoter region of GhMPK16. The predicted transcription initiation site is indicated }(+1 \text {, A). The start } \\
\text { codon is marked with an asterisk, and the putative core promoter consensus sequences (TATA-box and CAAT-box) are highlighted in grey. The } \\
\text { putative cis-acting elements are indicated by boxes and their corresponding names are given above each element. Arrows indicate the direction } \\
\text { of the cis-element. Box-W1 is a fungal elicitor responsive element, ERE is an ethylene-responsive element, the MBS binding site is involved in } \\
\text { gene induction in response to drought-inducibility and the TCA-element is a cis-acting element involved in SA-responsive. }\end{array}$} \\
\hline
\end{tabular}

leaves was lower for transgenic line \#2 than for transgenic line \#5. These results indicate that GhMPK16 can enhance resistance to $P$. solanacearum in a dose-dependent manner in transgenic plants. In order to better understand the role of GhMPK16 in disease resistance in transgenic plants, three marker genes associated with pathogen responses (AtPR1, AtPR4, and AtPDF1.2) were selected, and the transcript levels of those genes were analyzed by reverse transcription-PCR (RT-PCR). The expression of the three marker genes, especially AtPR4 and AtPDF1.2, was more rapidly and strongly induced by the $P$. solanacearum infection in transgenic plants than in wild-type plants (Figure 6D). These results demonstrate that the overexpression of GhMPK16 activates defense-related gene expression when plants are challenged with $P$. solanacearum.

As shown in Figure 7, GhMPK16-overexpressing plants were evaluated for their resistance to fungal pathogens (C. nicotianae and A. alternate). Detached leaves were inoculation with $C$. nicotianae and A. alternate, and after 5 days, the lesions in the wild-type leaves were larger than those in the transgenic leaves, and line \#2, which displayed the highest level of GhMPK16 expression, exhibited the least severe disease symptoms. To quantify the lesions, the diameters of the disease spots were measured, and the data were consistent with the visual observations. These results indicate that GhMPK16 can enhance resistance to infections by pathogenic fungi in transgenic plants. After inoculating whole plants with $C$. nicotianae and A. alternate, the expression of AtPR1, AtPR4 and AtPDF1.2 was observed at 3- and 6-day post-infection in both the wild-type and transgenic plants, and the expression patterns of the three marker genes were similar to those observed with the $P$. solanacearum challenge (data not shown).

\section{Reduced drought tolerance and rapid $\mathrm{H}_{2} \mathrm{O}_{2}$ accumulation} in GhMPK16-overexpressing plants

Compared with wild-type plants, the GhMPK16-overexpressing plants exhibited obvious drought sensitivity. As shown in Figure 8A, the leaves began to turn yellow and curl in both the 3-week-old wild-type and transgenic plants after a 15-day drought treatment. Additionally, drought treatment led to more serious damage in the transgenic plants than in the wild-type plants. Under normal conditions, no overt morphological differences were observed between wild-type and transgenic plants (data not shown). We tested the seed germination capacity on 1/2 MS agar medium with $50 \mathrm{mM}$ mannitol to mimic drought conditions and found that the germination percentage was higher for wild-type plants than for transgenic plants (Figure 8B, C). The root lengths of both wild-type 


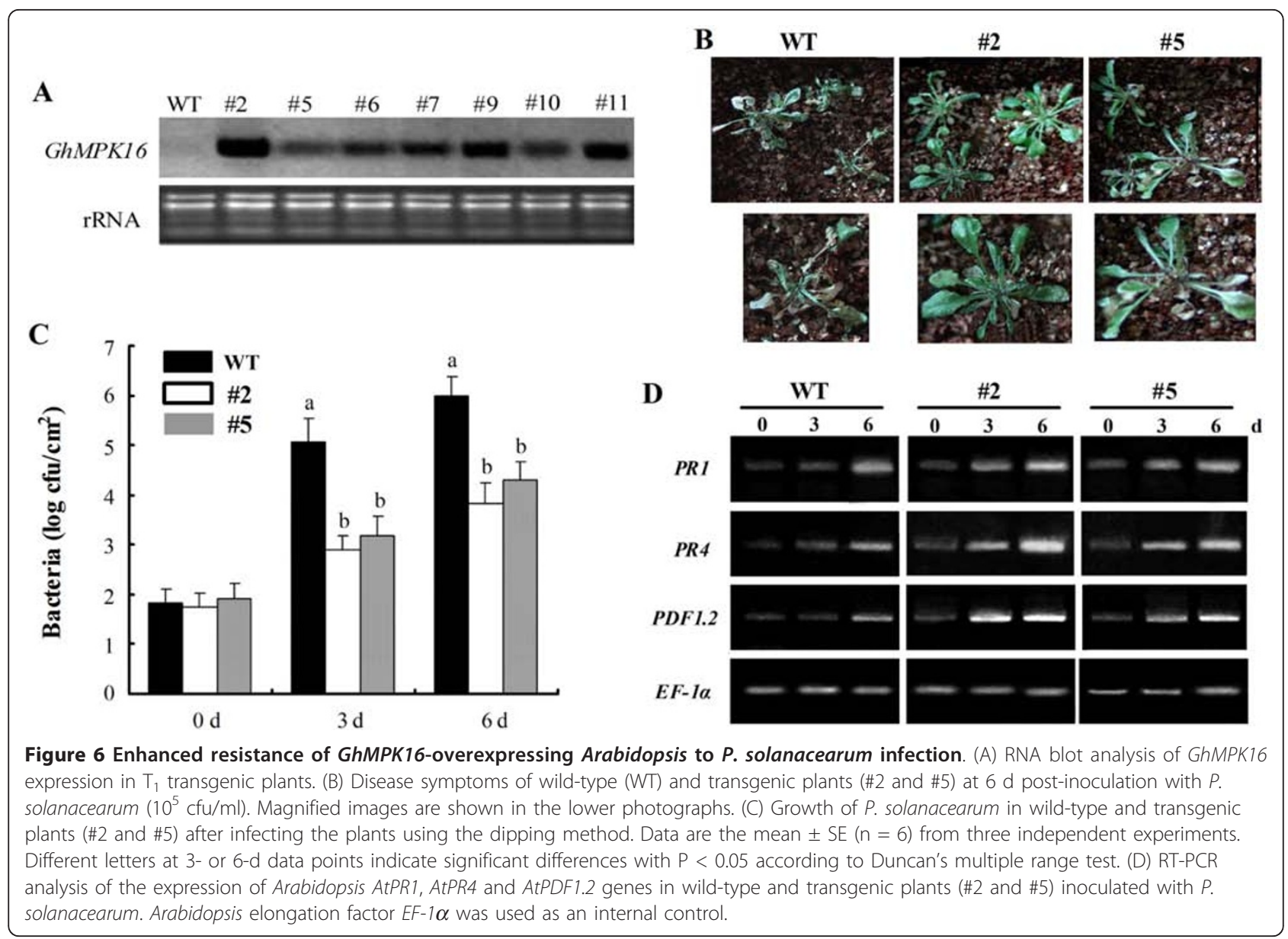

and transgenic plants were used as indicators of drought stress tolerance. Root growth was inhibited by mannitol treatment to a greater extent in transgenic seedlings than in wild-type seedlings (Figure 8D, E). These results suggest that the overexpression of GhMPK16 in Arabidopsis results in reduced drought tolerance.

One of the important responses of plants under osmotic stress is the accumulation of reactive oxygen species (ROS). Among the different ROS, only $\mathrm{H}_{2} \mathrm{O}_{2}$ can cross plant membranes and thus directly function in cell-tocell signaling. Therefore, we examined endogenous $\mathrm{H}_{2} \mathrm{O}_{2}$ accumulation in wild-type and transgenic plants in response to mannitol treatment. Mannitol (200 mM) was used to treat one-week-old seedlings, and the leaves were collected after $0,1,3$ and 6 h. Staining with 3,3'diaminobenzidine (DAB) revealed different levels of $\mathrm{H}_{2} \mathrm{O}_{2}$ production in the leaves of wild-type and transgenic plants after osmotic stress treatment. Specifically, $\mathrm{H}_{2} \mathrm{O}_{2}$ accumulated in transgenic plants at a significantly faster speed than that in wild-type plants (Figure 9). These results suggest that the overexpression of GhMPK16 leads to the rapid production of ROS or ineffective scavenge of excess ROS after osmotic stress.

\section{Discussion and Conclusion}

In this study, we isolated and characterised GhMPK16, a gene whose product belongs to the family of group $D$ MAPKs. GhMPK16 is the first characterized MAPK gene from cotton belonging to the group D MAPKs. The corresponding protein is characterized by the presence of a TDY activation motif in its T-loop, the lack of a $C D$ domain and an extended C-terminal region compared to the TEY subtypes of MAPKs (Figure 1A). These structural differences suggest that group D MAPKs may function differently from other MAPKs.

The subcellular localization of group D MAPKs has not been established. OsBWMK1, a group D MAPK from rice, is found in the nucleus and mediates pathogenesis-related gene expression by activating the OsEREBP1 transcription factor [11]. Intriguingly, the alternative splicing of $O s B W M K 1$ generates three different transcriptional variants that produce proteins with different subcellular localizations [15]. In Arabidopsis, AtMPK18 is located in the cytoplasm [14]. Analysis of the subcellular localization of a GFP-tagged GhMPK16 protein in transiently transformed onion epidermal cells revealed that GhMPK16 is likely localized in the nucleus 


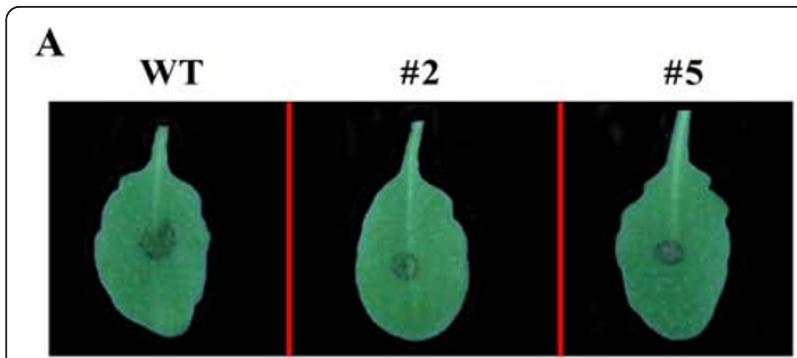

B

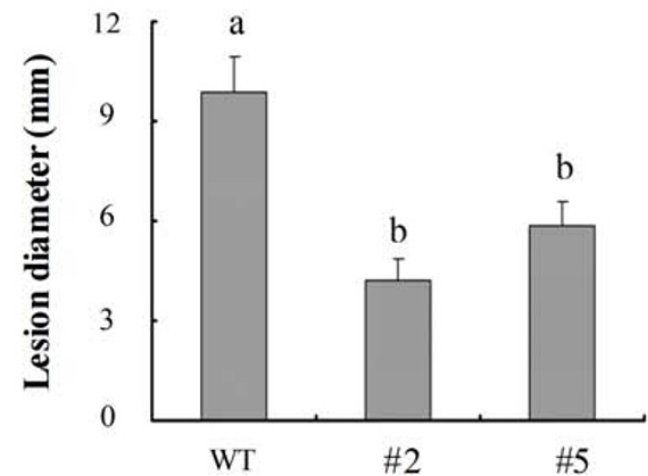

C

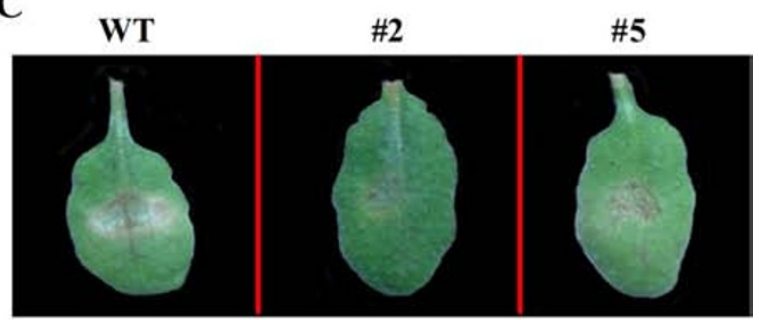

D

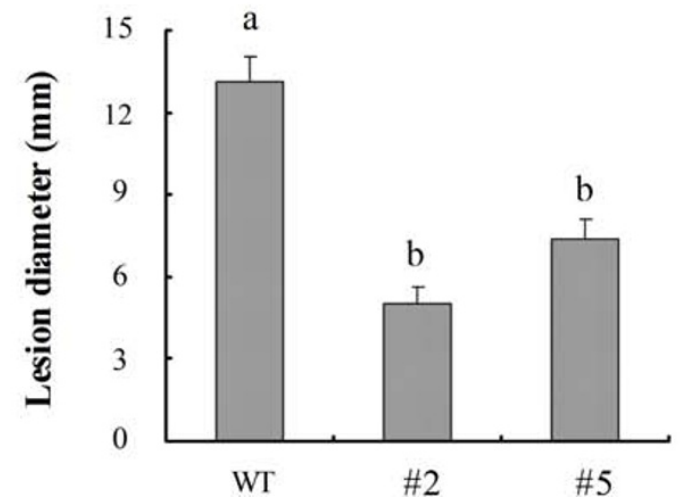

Figure 7 Inhibition of fungal pathogen infections in GhMPK16-overexpressing Arabidopsis lines. (A) Disease symptoms of leaves from wild-type (WT) and transgenic plants (\#2 and \#5) $5 \mathrm{~d}$ after inoculation with C. nicotianae $\left(10^{6} \mathrm{conidia} / \mathrm{ml}\right)$. (B) The diameter ( $\mathrm{mm}$ ) of the lesions was measured $5 \mathrm{~d}$ after inoculation with $C$. nicotianae. Data are the mean $\pm \mathrm{SE}(n=6)$ from three independent experiments. Different letters indicate significant differences with $\mathrm{P}<0.05$ according to Duncan's multiple range test. (C) Disease symptoms of the leaves from wild-type (WT) and transgenic plants (\#2 and \#5) $5 \mathrm{~d}$ after inoculation with A. alternate $\left(10^{6} \mathrm{conidia} / \mathrm{ml}\right)$. (D) The diameter ( $\mathrm{mm}$ ) of the lesions was measured 5 $\mathrm{d}$ after inoculation with $A$. alternate. Data are the mean $\pm \mathrm{SE}(n=6)$ from three independent experiments. Different letters indicate significant differences with a $P<0.05$ according to Duncan's multiple range test.

(Figure 3). Therefore, we speculated that GhMPK16 may act as a transcriptional activator by activating the expression of a set of target genes in the nucleus.

Gene expression patterns are usually an indicator of gene function. Notably, GhMPK16 can be induced by various pathogens, including $X$. campestris pv. malvacearum, R.solani and C. gossypii. RNA blot analyzes revealed that the expression of GhMPK16 could be induced by signal molecules such as SA, MeJA, and ABA (Figure 4). These results imply that GhMPK16 may play a role in plant defense responses and in the regulation of certain components of multiple stress-signaling pathways. Consistent with this hypothesis, sequence analysis of the GhMPK16 promoter revealed several motifs, such as Box-W1 element, ERE element and TCA-element, related to motifs with important roles in defense signaling.

Recently, a variety of MAPK genes have been identified and subsequently explored by both genetic and biochemical approaches. Increasing evidence has shown that the MAPK cascade is an important pathway in pathogen-triggered signal transduction [16,17]. Signal molecules such as SA, jasmonic acid (JA) and ethylene (ET), regulate distinct sets of pathogenesis-related (PR) genes in different pathogen defense pathways. SA and MeJA are involved in two major defense signaling pathways, the SA-dependent and JA/ET-dependent defense mechanisms, which act against different types of pathogens [18]. In Arabidopsis, AtMPK4 responds to the balance between SA and MeJA through the EDS1/PAD4 module and regulates the SA and JA/ET-related defense responses [19]. When GhMPK16 is ectopically expressed in Arabidopsis, the transgenic Arabidopsis show enhanced disease resistance against bacteria ( $P$. solanacearum) and fungi (C. nicotianae and A. alternate) (Figure 6,7$). P R 1$ is known as a marker gene for the SA signaling pathway, and AtPR4 and AtPDF1.2 are markers for the JA/ET signaling pathway. Along with the enhanced disease resistance in GhMPK16-overexpressing plants, the expression of the examined defenserelated genes AtPR1, AtPR4, and AtPDF1.2 was elevated. Thus, it is reasonable to speculate that GhMPK16 may be involved in the crosstalk between the SA- and JA/ ET- mediated pathogen defense pathways.

GhMPK16 showed a response to various abiotic stresses, such as low or high temperatures, mannitol and $\mathrm{NaCl}$ (Figure 4). Interestingly, transgenic plants overexpressing GhMPK16 exhibited obvious drought sensitivity 


\section{A}
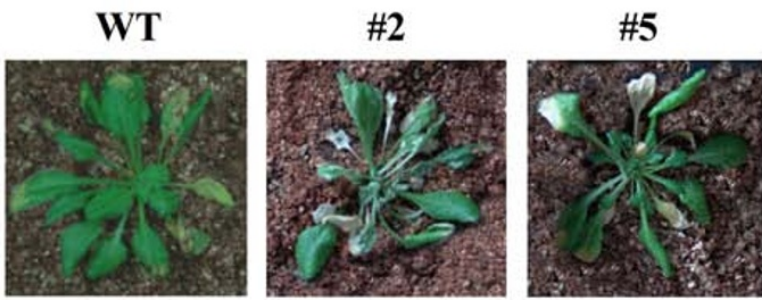

B

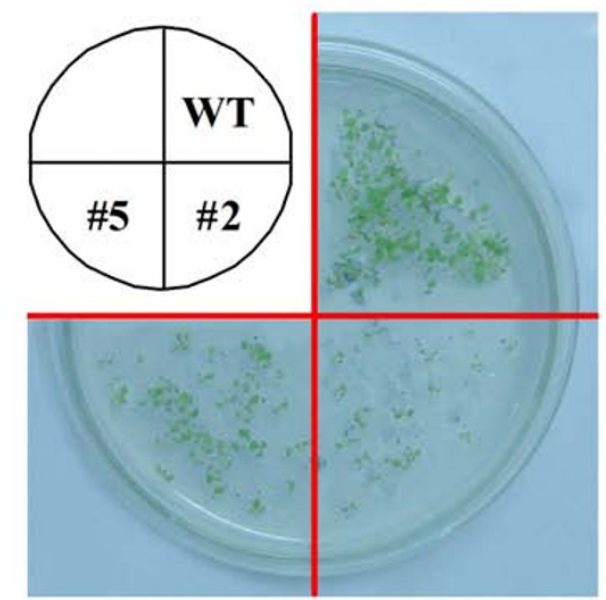

C

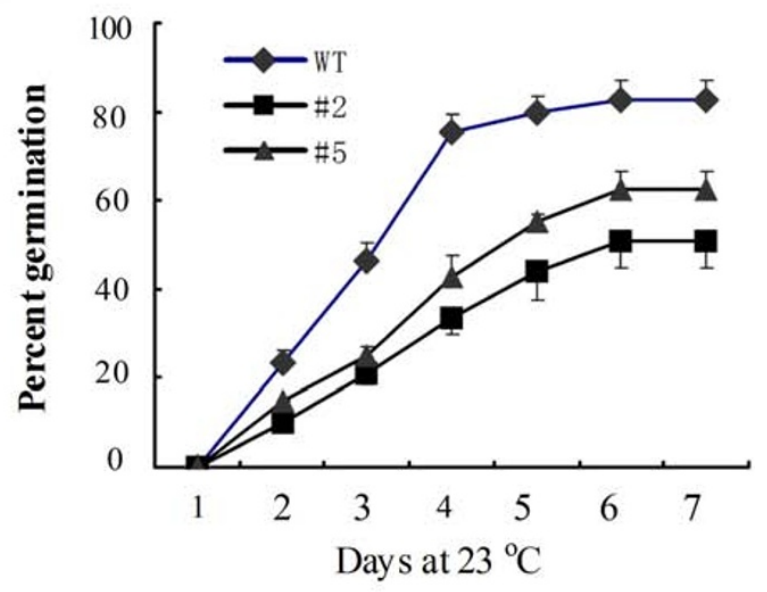

$\mathbf{E}$

D

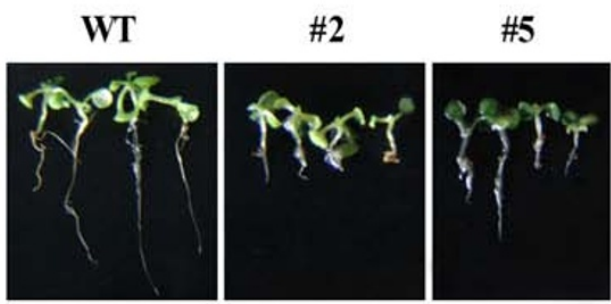

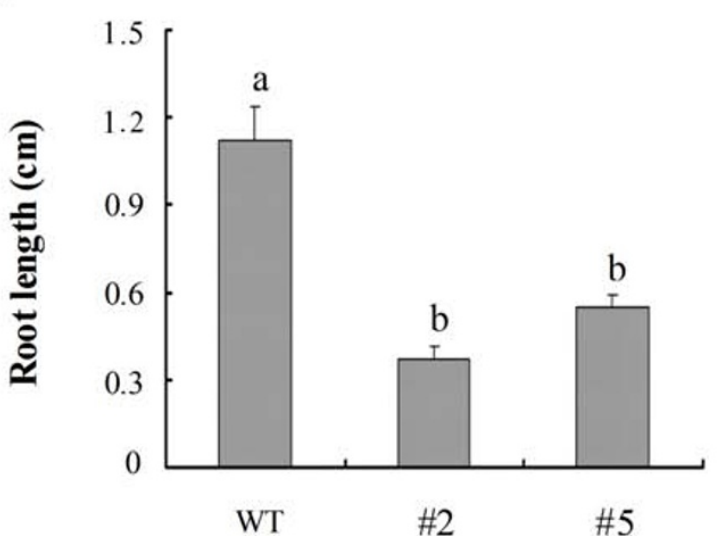

Figure 8 Drought stress analysis of GhMPK16-overexpressing Arabidopsis. (A) Phenotypes of wild-type (WT) and transgenic plants (\#2 and \#5) plants withheld from water for $15 d$ at the vegetative stage. (B) Seed germination of wild-type (WT) and transgenic plants (\#2 and \#5) after 4 days on 1/2 MS agar medium containing $50 \mathrm{mM}$ mannitol. (C) Germination percentage of seeds on 1/2 MS agar medium containing $50 \mathrm{mM}$ mannitol. Germination was defined as the emergence of the root radical and was scored daily. Data are the mean $\pm S E(n=4)$ from three independent experiments. (D) Growth of wild-type (WT) and transgenic plant (\#2 and \#5) seedlings after $100 \mathrm{mM}$ mannitol treatment. Photos were taken $10 \mathrm{~d}$ after mannitol treatment. (E) Root length of wild-type (WT) and transgenic plant (\#2 and \#5) seedlings after $100 \mathrm{mM}$ mannitol treatment for $12 \mathrm{~d}$. Data are the mean $\pm \mathrm{SE}(\mathrm{n}=6)$ from three independent experiments. Different letters indicate significantly different at $P<$ 0.05 according to Duncan's multiple range test. 


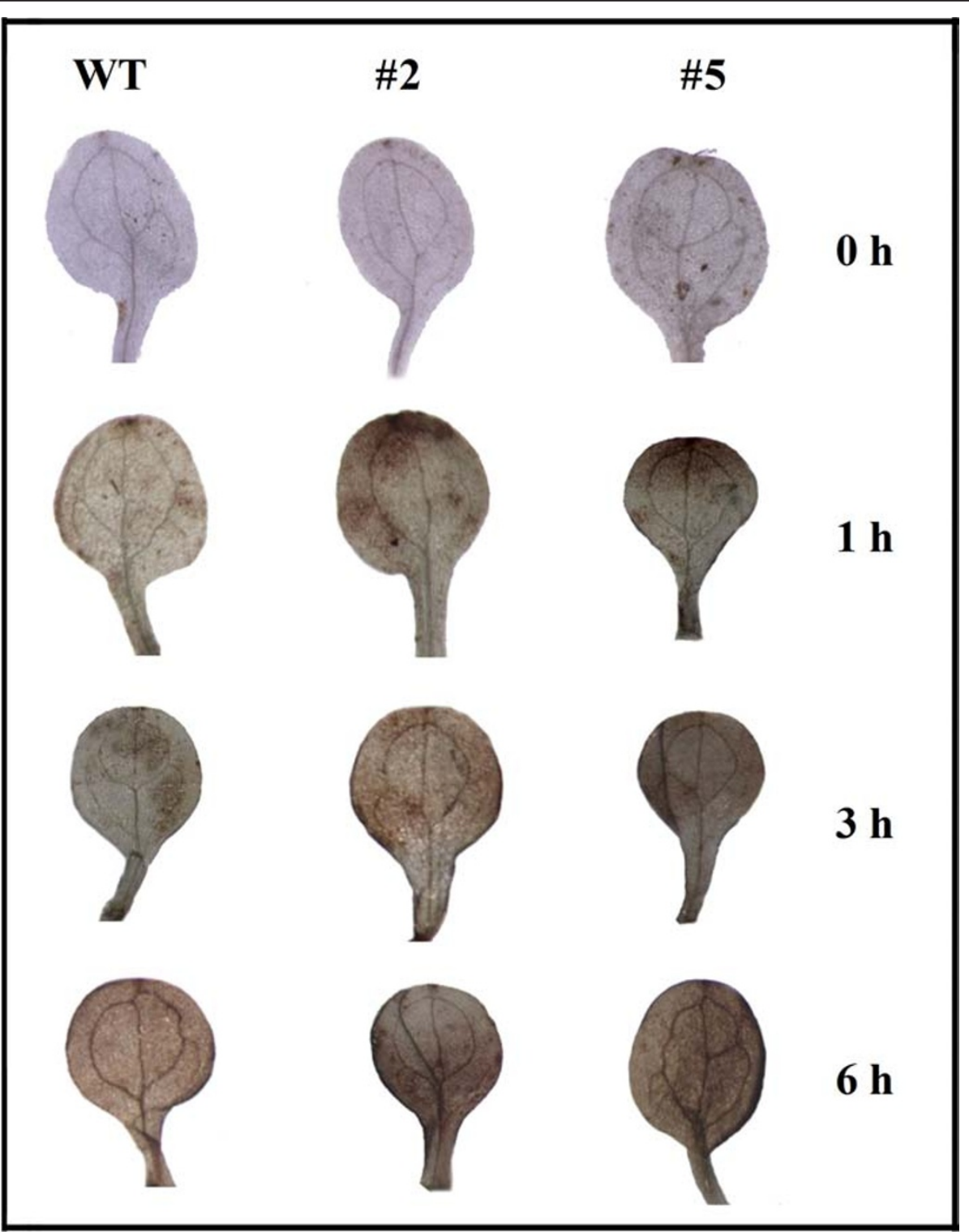

Figure 9 DAB coloration assay of $\mathrm{H}_{2} \mathrm{O}_{2}$ accumulation in wild-type (WT) andGhMPK16-overexpressing transgenic plants after $200 \mathrm{mM}$ mannitol treatment. Mannitol was used to treat one-week-old plants for $0,1,3$ or $6 \mathrm{~h}$.

(Figure 8). GhMPK16 overexpression resulted in a significant reduction in both germination percentage and root growth after mannitol treatment, and seedling growth was more severely inhibited by drought stress in GhMPK16-overexpressing plants than in wild-type plants. ABA responds to the environmental signals to protect plants from abiotic stresses, such as cold, drought and salt stresses [20,21]. The expression of GhMPK16 was strongly induced by exogenous ABA and the GhMPK16-overexpressing plants were sensitive to drought tolerance comparing with wild-type Arabidopsis, suggesting that GhMPK16 may be involved in ABA signaling and caused negative function for drought tolerance. DAB staining revealed that $\mathrm{H}_{2} \mathrm{O}_{2}$ rapidly accumulation in GhMPK16-overexpressing transgenic plants after drought treatment (Figure 9). Excessive ROS can injure plants. GhMPK16 accelerates the accumulation of $\mathrm{H}_{2} \mathrm{O}_{2}$, and this may be the reason that drought causes more serious damage in the transgenic plants. In Arabidopsis, MPK9 and MPK12 function downstream of ROS to regulate guard cell ABA signaling positively [13]. Guard cell-specific inhibition of Arabidopsis MPK3 expression causes abnormal stomatal responses to ABA and $\mathrm{H}_{2} \mathrm{O}_{2}$ [22]. More physiological, biochemical and molecular experiments are needed to elucidate the mechanism of GhMPK16 in response to drought stress. 
On the basis of these observations, we propose that GhMPK16 functions in at least two signaling pathways, one that responds to pathogens and another that is involved in drought stress. GhMPK16 may serve as a point for crosstalk between biotic and abiotic stress response signaling. Further studies on the function and regulation of GhMPK16 are required.

\section{Methods}

\section{Plant materials and treatments}

The cotton cultivar Gossypium hirsutum L. cv Lumian 22 was used for all of the experiments. Germinated seedlings were grown by aquaculture in tissue culture pots (sterile water) under greenhouse conditions at $25^{\circ} \mathrm{C}$ with a $16 \mathrm{~h}$ light $/ 8 \mathrm{~h}$ dark cycle. The following treatments were performed on seven-day-old cotton seedlings: $10 \mathrm{mM} \mathrm{Sal-}$ icylic acid (SA), $100 \mu \mathrm{M}$ methyl jasmonate (MeJA) (ethanol as a solvent control) or $100 \mu \mathrm{M}$ abscisic acid (ABA) was sprayed onto leaves of cotton seedlings; seedling roots were placed in $200 \mathrm{mM} \mathrm{NaCl}$ and $200 \mathrm{mM}$ mannitol solutions for salt and drought stresses, respectively; seedling leaves were cut with scissors for wound treatment; seedlings were placed in a growth chamber at $37^{\circ} \mathrm{C}$ or $12^{\circ} \mathrm{C}$ for the high and low temperature treatments, respectively; roots were dipped into suspensions of the bacterial pathogen Xanthomonas campestris pv. malvacearum (X. campestris pv. malvacearum) $(\mathrm{OD}=$ 0.001 ) to cause a bacterial infection and the fungal pathogens Fusarium oxysporum f. sp. vasinfectum (F. oxysporum f. sp. vasinfectum) and Colletotrichum gossypii (C. gossypii) conidial suspensions $\left(10^{5}\right.$ conidia/ml $)$ in $1 \%$ glucose were dropped onto plant leaves to cause the fungal infections. The plants treated with $1 \%$ glucose were considered as mock. The leaves, roots and stems were harvested at the appropriate time points as indicated and frozen in liquid nitrogen for further analyzes.

Arabidopsis (ecotype Columbia, Col-0) and transgenic Arabidopsis seeds were planted directly in soil or transplanted after germinating on 1/2 MS agar medium and grown in a chamber under SD ( $8 \mathrm{~h}$ light/16 h dark) or $\mathrm{LD}\left(16 \mathrm{~h}\right.$ light $/ 8 \mathrm{~h}$ dark) conditions at $23^{\circ} \mathrm{C}$. All seeds were treated at $4^{\circ} \mathrm{C}$ for $2 \mathrm{~d}$ before being transferred to a growth chamber. Arabidopsis were grown in SD conditions for 2-week and then transferred to LD conditions. 3-week-old Arabidopsis plants were used for the disease resistance assays. The bacterial pathogen Pseudomonas solanacearum ( $P$. solanacearum) was cultivated in King's $\mathrm{B}$ medium at $30^{\circ} \mathrm{C}$ for 2 days, and the bacterial cells were resuspended in $10 \mathrm{mM} \mathrm{MgCl} 2$ to a concentration of $10^{5}$ colony-forming units $/ \mathrm{ml}(\mathrm{cfu} / \mathrm{ml})$. Plants were infected using the dipping method, and bacterial titres were assessed by plating a dilution series of leaves ground in $10 \mathrm{mM} \mathrm{MgCl}$ on King's $\mathrm{B}$ medium as described by Liu et al. [23]. Infected leaves were sampled immediately and at 3- and 6-d after inoculation. To evaluate resistance against the fungal pathogens Colletotrichum nicotianae (C. nicotianae) and Alternaria alternate (A. alternate), two methods were used: the detached leaf inoculation assay and the whole plant inoculation assay. A spore suspension $\left(10^{6}\right.$ conidia/ml $)$ was prepared in $1 \%$ glucose. In the detached leaf inoculation assay, leaves were inoculated with a $10 \mu \mathrm{l}$ droplet of conidial suspension. In the whole plant inoculation assay, a vaporiser was used to inoculate the plants with the conidial suspension. The inoculated leaves and plants were kept in a moist chamber under dark conditions at $25^{\circ} \mathrm{C}$ for $48 \mathrm{~h}$ and then incubated under LD conditions at $25^{\circ} \mathrm{C}$.

For the drought stress tolerance analysis, Arabidopsis were grown in SD conditions for 2-week and then transferred to LD conditions. For 15 d, 3-week-old Arabidopsis plants were completely withheld from water. Additionally, Arabidopsis seeds were germinated in 1/2 MS agar medium or 1/2 MS agar medium supplemented with $50 \mathrm{mM}$ mannitol. Analysis of the growth of transgenic Arabidopsis after mannitol treatment, Arabidopsis seeds germinated in 1/2 MS agar medium and incubated for $3 \mathrm{~d}$. The seedlings were then carefully transferred into 1/2 MS agar medium supplemented with $100 \mathrm{mM}$ mannitol, and root lengths were measured over the next $10 \mathrm{~d}$.

\section{Cloning of the GhMPK16 gene}

Total RNA was extracted from cotton seedling leaves using TRIzol Reagent (Invitrogen, Carlsbad, CA, USA) according to the manufacturer's protocol. The fulllength GhMPK16 cDNA was amplified by reverse transcription-PCR (RT-PCR) and rapid amplification of cDNA ends-PCR (RACE-PCR).

The first cDNA strand was synthesised using approximately $2 \mu \mathrm{g}$ of total RNA, the Oligo $(\mathrm{dT})_{18}$ adaptor primer and M-MLV reverse transcriptase (Promega, Madison, WI, USA) for $1 \mathrm{~h}$ at $42^{\circ} \mathrm{C}$. To clone the internal conserved fragment, primers MP1 and MP2 were designed and synthesised based on the conserved amino acid and nucleotide sequences of the plant group D MAPK genes. Cloning was performed as described previously [24], and the primer sequences are provided in Table 1.

Amino acid and nucleotide sequences of other plant MAPK genes were retrieved from GenBank (http:// www.ncbi.nlm.nih.gov/Genbank). Amino acid sequence alignments were performed using the DNAman 6.0 program. The phylogenetic tree was constructed by the Neighbour-Joining method using MEGA 4.

\section{Amplification of the GhMPK16 genomic sequence}

Total genomic DNA was extracted from cotton seedlings using a modified cetyl-trimethyl-ammonium 
bromide (CTAB) method [25]. The genomic DNA of cotton was isolated to clone the DNA sequence and the 5'-flanking region of GhMPK16.

Two genomic DNA fragments were PCR amplified with primers designed according to the GhMPK16 cDNA sequence. The first fragment was amplified with primers FL1 and Z1, and the second fragment was amplified with primers FL2 and Z2.

The promoter region was cloned using the inversePCR (I-PCR) method. Five restriction endonucleases (Bam I, Bgl II, Dra I, Hind III and Xba I) were used to digest the genomic DNA. Using T4 DNA ligase (TaKaRa, Dalian, China), the DNA fragments were selfligated to form circles that were used as the template to amplify the GhMPK16 promoter region. The 5' flanking region of GhMPK16 was obtained from the template digested with Dra I. The exterior primers Wup1 and Wdra1 and the interior primers Wup2 and Wdra2 were used for the first and second rounds of PCR, respectively. The sequences of the primers used in this study are provided in Table 1 . The PlantCARE program (http://bioinformatics.psb.ugent.be/webtools/plantcare/ html) was used to analyze the GhMPK16 promoter sequences, which used default parameters.

\section{Subcellular localization and Histochemical Analysis}

To observe the cellular localization of GhMPK16, the GhMPK16::GFP fusion construct was prepared. The GhMPK16 coding region was amplified with primers Wbd- 1 and W-GFP, containing an Xba I site upstream and an Xho I site downstream of the deleted stop codon, respectively. The resulting fragment was inserted into the $X b a \mathrm{I} / X h o$ I site of the binary vector pBI121-GFP, and the fragment was fused to GFP and placed under the control of the cauliflower mosaic virus (CaMV) $35 \mathrm{~S}$ promoter. Particle bombardment was performed according to the manufacturer's instructions (PDS-1000, Bio-Rad Laboratories, Hercules, CA), using gold particles $(1.0 \mu \mathrm{l})$ and 1350 psi helium pressure. After bombardment, tissues were incubated on MS agar medium under dark conditions at $23^{\circ} \mathrm{C}$ for $12 \mathrm{~h}$. Nuclei were stained with 100 $\mu \mathrm{g} / \mathrm{ml}$ of 4',6-diamidino-2-phenylindole (DAPI) (Solarbio, Beijing, China) in phosphate-buffered saline for $10 \mathrm{~min}$. GFP fluorescence and DAPI fluorescence were examined with a laser scanning microscope (LSM 510 META, ZEISS, Germany) using excitation wavelengths of $488 \mathrm{~nm}$ and $350 \mathrm{~nm}$, respectively.

\section{Immunoblot analysis}

The GhMPK16::GFP recombinant plasmid was introduced into the Agrobacterium tumefaciens strain GV3101. The A. tumefaciens strains were grown overnight in YEB media. Pellet and resuspended cells was performed as described by Guo [26]. Resuspended cells were infiltrated into leaves of 4-week-old Nicotiana benthamiana plants as described previously $[27,28]$. Epidermal cell layers of plant leaves were assayed for fluorescence with a fluorescence microscope (BX51, model 7.3; Olympus) $3 \mathrm{~d}$ after injection. Total plant proteins were extracted as Silverstone described [29]. The proteins were separated by sodium dodecyl sulphate-polyacrylamide gel electrophoresis (SDS-PAGE) (12\%) and analyzed on immunoblots using a 1000-fold dilution of anti-GFP polyclonal antibodies (Beyotime, Haimen, China) and a 5000-fold dilution of horseradish peroxidase-conjugated goat anti-rabbit IgG (Beyotime). The signals were detected by chemiluminescence.

\section{Southern blot hybridisation}

Genomic DNA (30 $\mu \mathrm{g} / \mathrm{sample})$ was digested with EcoR V, EcoR I, Xba I or Hind III then separated on $0.8 \%$ agarose gels by electrophoresis and transferred onto a Hybond- $\mathrm{N}^{+}$Nylon membrane (Amersham, Pharmacia, $\mathrm{UK})$. A gene-specific dCTP- $\left[\alpha-{ }^{32} \mathrm{P}\right]$-labelled probe was synthesised with the GhMPK16 fragment (primers FL1 and 5P2) using the Primer-a-Gene ${ }^{\circledR}$ Labeling System (Promega, Madison, WI, USA) according to the manufacturer's instruction. The hybridisation was carried out for $24 \mathrm{~h}$ at $42^{\circ} \mathrm{C}$. After the hybridisation, the blots were washed two times with $2 \times$ SSC, $0.1 \%$ SDS and three times with $0.2 \times \mathrm{SSC}, 0.1 \% \mathrm{SDS}$ for $10 \mathrm{~min}$ each at $42^{\circ}$ $\mathrm{C}$, and the radioactive signal was visualised using a FLA-7000 phosphorimager (FUJIFILM).

\section{RNA blot hybridisation and semi-quantitative RT-PCR analyzes}

Total RNA was isolated from cotton seedling leaves using the method described above. Total RNA $(15 \mu \mathrm{g})$ from each sample was separated on a 1.0\% agarose-formaldehyde gel and transferred to Hybond- $\mathrm{N}^{+}$Nylon membranes (Amersham, Pharmacia, UK). Gene-specific dCTP- $\left[\alpha-{ }^{32} \mathrm{P}\right]$-labelled probe was synthesis (primers FL2 and 5P3) and RNA blot hybridisation were performed using the methods described for the Southern blot hybridisation.

To analyze gene expression in transgenic plants by RT-PCR, total RNA was isolated from wild-type and transgenic plants using the method described above for gene cloning. Amplifications were performed at $94^{\circ} \mathrm{C}$ for $5 \mathrm{~min}$, followed by $25-30$ cycles of amplification $\left(94^{\circ} \mathrm{C}\right.$ for $50 \mathrm{~s}, 50^{\circ} \mathrm{C}$ for $50 \mathrm{~s}$, and $72^{\circ} \mathrm{C}$ for $40 \mathrm{~s}$ ). The PCR products were separated on a $1.8 \%$ agarose gel and visualised after ethidium bromide staining. To ensure that equal cDNA amounts were used in each reaction, $E F-1 \alpha$ was used as a loading control. The gene-specific primers used in RT-PCR analyzes are listed in Table 1. 
Table 1 The primers used in this study

\begin{tabular}{|c|c|c|}
\hline Abbreviation & Sequence $\left(5^{\prime}-3^{\prime}\right)$ & Description \\
\hline MP1 & AARGGNAGYTAYGGNGTNGT & Degenerate primer, forward \\
\hline MP2 & $\begin{array}{l}\text { GCNACRTARTCNGTCCARAA }(\mathrm{H}=\mathrm{A}, \mathrm{C} \text {, or } \mathrm{T} ; \mathrm{N}=\mathrm{A}, \mathrm{C}, \mathrm{G} \text {, or } \mathrm{T} ; \mathrm{R}=\mathrm{A} \text { or } \\
\mathrm{G} ; \mathrm{V}=\mathrm{A}, \mathrm{C} \text {, or } \mathrm{G} ; \mathrm{Y}=\mathrm{C} \text { or } \mathrm{T})\end{array}$ & Degenerate primer, reverse \\
\hline 3P1 & TTCTTAATCAGCTTCTTCGGG & 3' RACE reverse primer, outer \\
\hline $3 \mathrm{P} 2$ & TTCATCGGGATCTAAAGCCG & $3^{\prime}$ RACE reverse primer, nested \\
\hline B26 & GACTCGAGTCGACATCGAT $($ T) 18 & Universal primer, outer \\
\hline B25 & GACTCGAGTCGACATCGAT & Universal primer, nested \\
\hline $5 \mathrm{P} 1$ & GAAGGAGGGAACAATATGTGC & 5' RACE reverse primer, outer \\
\hline $5 P 2$ & ATGACGTAGGAGCCTGAGAAG & 5' RACE reverse primer, nested \\
\hline AAP & GGCCACGCGTCGACTAGTAC $(\mathrm{G})_{14}$ & Abridged anchor primer \\
\hline AUAP & GGCCACGCGTCGACTAGTAC & Abridged universal amplification primer \\
\hline FL1 & GATGCTAAGATGCAGCCTGATC & Full-length cDNA primer \\
\hline FL2 & GCTTCACTTGTAACTTGTCTGAGC & Full-length cDNA primer \\
\hline $\mathrm{Z1}$ & CCGCACTTGGATACATGAAGCC & Genomic sequence primer \\
\hline Z2 & GAGTATCTGGAAGGATCAGAGCC & Genomic sequence primer \\
\hline $5 \mathrm{P3}$ & GCTGCCAGACCTGGGAAAGTAG & primer used for probe synthesized \\
\hline Wup1 & CACGCCATTAAACCAAGTAG & I-PCR primer \\
\hline Wdra1 & GAGGTTGACTAACACTAGTG & I-PCR primer \\
\hline Wup2 & GATCAGGCTGCATCTTAGCATC & I-PCR primer \\
\hline Wdra2 & AGCGTATGACACGCATACTG & I-PCR primer \\
\hline Wbd-1 & 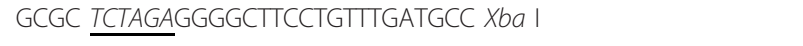 & Coding region primer \\
\hline Wbd-2 & GCGC GTCGACCCTCAACCAGCAGTAGGAAG Sal I & Coding region primer \\
\hline W-GFP & 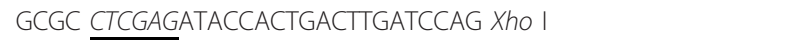 & Coding region primer \\
\hline AtEF-1 $\alpha-F$ & ATGGGTAAAGAGAAGTTTCACAT & RT-PCR primer \\
\hline AtEF-1 $\alpha-R$ & CTTGTTACAACAGCAGATCAT & RT-PCR primer \\
\hline AtPR1-F & GACGAGAGGGTTGCAGCCTATG & RT-PCR primer \\
\hline AtPR1-R & GATTCTCGTAATCTCAGCTCT & RT-PCR primer \\
\hline AtPR4-F & ССACСTACCATTTCTATAATCC & RT-PCR primer \\
\hline AtPR4-R & CACAGTCGAGAAATTGGTAGTC & RT-PCR primer \\
\hline AtPDF1.2-F & TCATGGCTAAGTTTGCTTCC & RT-PCR primer \\
\hline AtPDF1.2-R & AATACACACGATTTAGCACC & RT-PCR primer \\
\hline
\end{tabular}

\section{Vector construction and plant transformation}

The GhMPK16 coding region was amplified using primers Wbd-1 and Wbd-2 (Table 1). The amplified fragment was then subcloned into the binary vector pBI121 under the control of the CaMV $35 \mathrm{~S}$ promoter. The recombinant plasmid was introduced into the $A$. tumefaciens strain GV3101. Arabidopsis was transformed using the floral dip method [30]. Transformants were selected on $1 / 2 \mathrm{MS}$ agar medium containing $30 \mu \mathrm{g} / \mathrm{ml}$ of kanamycin. The transgenic $T_{3}$ lines were used in the experiments.

\section{Histochemical detection of $\mathrm{H}_{2} \mathrm{O}_{2}$}

The substrate, 3,3'-diaminobenzidine (DAB), was used to visually detect $\mathrm{H}_{2} \mathrm{O}_{2}$ in plants [31]. Arabidopsis plants (one-week-old) were treated with $200 \mathrm{mM}$ mannitol for $0,1,3$, and $6 \mathrm{~h}$. The samples were incubated in $1 \mathrm{mg} /$ $\mathrm{ml}$ DAB solution $(\mathrm{pH} 3.8)$ for $6 \mathrm{~h}$, and then treated with
95\% ethanol to remove chlorophyll. In the presence of $\mathrm{H}_{2} \mathrm{O}_{2}$, DAB is locally polymerised and produces visible brown stain.

\section{Additional material}

Additional file 1: Figure S1 Schematic representation of the genome structure of GhMPK16. Length of the exons and introns (A) Arabidopsis thaliana (AtMPK16), (B) Gossypium hirsutum (GhMPK16), (C) Oryza sativa (Os11g0271100), and (D) Vitis vinifera (Vitis vinifera hypothetical protein LOC100246022) are indicated according to the scale below. The exons and introns are highlighted with gray and white bars, respectively. The start codons (ATG) are indicated by $(\mathbf{v})$, and the stop codons are marked by $\left.{ }^{*}\right)$.

Additional file 2: Figure S2. Analysis of the integrity of GhMPK16::GFP fusion protein. (A) Transient expression of 35S-GFP and 35S-GhMPK16::GFP in $N$. benthamiana cells. Bar $=10 \mu \mathrm{m}$. (B) Immunoblot analysis of GhMPK16::GFP fusion protein. 4-week-old N. benthamiana plants were chosen, and proteins were isolated from wild-type and transgenic plant leaves. Each lane was loaded with a total of $50 \mu \mathrm{g}$ protein. 


\section{Acknowledgements}

This work was financially supported by Genetically Modified Organisms Breeding Major Projects of China (2009ZX08009-092B; 2009ZX08009-113B) and Nation Natural Science Foundation of China (Grant no. 30970225)

\section{Authors' contributions}

JS carried out most of the experiments, and drafted the manuscript. LZ participated in southern blot analysis, RNA blot analysis and subcellular localization analysis of the study. HA, CW and XG conceived the experimental design and helped to draft the manuscript. All authors read and approved the final manuscript.

\section{Received: 12 October 2010 Accepted: 16 May 2011}

Published: 16 May 2011

\section{References}

1. Somssich IE: MAP kinases and plant defence. Trends Plant Sci 1997, 2:406-408.

2. Widmann C, Gibson S, Jarpe MB, Johnson GL: Mitogen-activated protein kinase: conservation of a three-kinase module from yeast to human. Physiol Rev 1999, 79:143-180.

3. Colcombet J, Hirt H: Arabidopsis MAPKs: a complex signaling network involved in multiple biological processes. Biochem J 2008, 413:217-226.

4. Group MAPK: Mitogen-activated protein kinase cascades in plants: a new nomenclature. Trends Plant Sci 2002, 7:301-308.

5. Hamel LP, Nicole MC, Sritubtim S, Morency MJ, Ellis M, Ehlting J, Beaudoin N, Barbazuk B, Klessig D, Lee J, Martin G, Mundy J, Ohashi Y, Scheel D, Sheen J, Xing T, Zhang SQ, Seguin A, Ellis BE: Ancient signals: comparative genomics of plant MAPK and MAPKK gene families. Trends Plant Sci 2006, 11:192-198.

6. Ortiz-Masia D, Perez-Amador MA, Carbonell J, Marcote MJ: Diverse stress signals activate the $\mathrm{C} 1$ subgroup MAP kinases of Arabidopsis. FEBS Lett 2007, 581:1834-1840

7. Ortiz-Masia D, Perez-Amador MA, Carbonell P, Aniento F, Carbonell J, Marcote MJ: Characterization of PsMPK2, the first C1 subgroup MAP kinase from pea (Pisum sativum L.). Planta 2008, 227:1333-1342.

8. Doczi R, Brader G, Pettko-Szandtner A, Rajh I, Djamei A, Pitzschke A, Teige $M$, Hirt H: The Arabidopsis mitogen-activated protein kinase kinase MKK3 is upstream of group C mitogen-activated protein kinases and participates in pathogen signaling. Plant Cell 2007, 19:3266-3279.

9. Shi J, An HL, Zhang L, Gao Z, Guo XQ: GhMPK7, a novel multiple stressresponsive cotton group C MAPK gene, has a role in broad spectrum disease resistance and plant development. Plant Mol Bio 2010, 74:1-17.

10. Reyna NS, Yang Y: Molecular analysis of the rice MAP Kinase gene family in relation to Magnaporthe grisea infection. Mol Plant Microbe Interact 2006, 19:530-540.

11. Cheong YH, Moon BC, Kim JK, Kim CY, Kim MC, Kim IH, Park CY, Kim JC, Park BO, Koo SC, Yoon HW, Chung WS, Lim CO, Lee SY, Cho MJ: BWMK1, a rice mitogen-activated protein kinase, locates in the nucleus and mediates pathogenesis-related gene expression by activation of a transcription factor. Plant Physiol 2003, 132:1961-1972.

12. Lalle M, Visconti S, Marra M, Camoni L, Velasco R, Aducci P: ZmMPK6, a novel maize MAP kinase that interacts with 14-3-3 proteins. Plant Mol Bio 2005, 59:713-722.

13. Jammes F, Song C, Shin D, Munemasa S, Takeda K, Gu D, Cho D, Lee S, Giordo R, Sritubtim S, Leonhardt N, Ellis BE, Murata Y, Kwak JM: MAP kinases MPK9 and MPK12 are preferentially expressed in guard cells and positively regulate ROS-mediated ABA signaling. Proc Natl Acad Sci USA 2009, 106:20520-20525

14. Walia A, Lee JS, Wasteneys G, Ellis B: Arabidopsis mitogen-activated protein kinase MPK18 mediates cortical microtubule functions in plant cells. Plant J 2009, 59:565-575.

15. Koo SC, Yoon HW, Kim CY, Moon BC, Cheong YH, Han HJ, Lee SM, Kang KY, Kim MC, Lee SY, Chung WS, Cho MJ: Alternative splicing of the OsBWMK1 gene generates three transcript variants showing differential subcellular localizations. Biochem Biophys Res Commun 2007, 360:188-193.

16. Zhang S, Klessig DF: MAPK cascades in plant defense signaling. Trends Plant Sci 2001, 6:520-527.

17. Nakagami H, Pitzschke A, Hirt H: Emerging MAP kinase pathways in plant stress signalling. Trends Plant Sci 2005, 10:339-346
18. Kunkel BN, Brooks DM: Cross talk between signaling pathways in pathogen defense. Curr Opin Plant Biol 2002, 5:325-331.

19. Brodersen P, Petersen M, Bjorn Nielsen H, Zhu S, Newman MA, Shokat KM Rietz S, Parker J, Mundy J: Arabidopsis MAP kinase 4 regulates salicylic acid- and jasmonic acid/ethylene-dependent responses via EDS1 and PAD4. Plant J 2006, 47:532-546

20. Zhu JK: Salt and drought stress signal transduction in plants. Annu Rev Plant Biol 2002, 53:247-273.

21. Xiong L, Schumaker KS, Zhu JK: Cell signaling during cold, drought, and salt stress. Plant Cell 2002, 14(Suppl: S):165-183.

22. Gudesblat GE, lusem ND, Morris PC: Guard cell-specific inhibition of Arabidopsis MPK3 expression causes abnormal stomatal responses to abscisic acid and hydrogen peroxide. New Phytol 2007, 173:713-721.

23. Liu H, Zhang H, Yang Y, Li G, Yang Y, Wang X, Basnayake BM, Li D, Song F: Functional analysis reveals pleiotropic effects of rice RING-H2 finger protein gene OSBIRF1 on regulation of growth and defense responses against abiotic and biotic stresses. Plant Mol Biol 2008, 68:17-30.

24. Wang MM, Zhang Y, Wang J, Wu XL, Guo XQ: A novel MAP Kinase gene in cotton (Gossypium hirsutum L.), GhMAPK, is involved in response to diverse environmental stresses. J Biochem Mol Biol 2007, 40:325-332.

25. Jeong MJ, Lee SK, Kim BJ, Kwon TR, Cho WS, Park YT, Lee JO, Kwon HB, Byun MO, Park SC: A rice (Oryza stativa L.) MAP kinase gene, OsMAPK44, is involved in response to abiotic stresses. Plant Cell Tissue Organ Cult 2006, 85:151-160.

26. Guo YH, Yu YP, Wang D, Wu CA, Yang GD, Huang JG, Zheng CC: GhZFP1, a novel $\mathrm{CCCH}$-type zinc finger protein from cotton, enhances salt stress tolerance and fungal disease resistance in transgenic tobacco by interacting with GZIRD21A and GZIPR5. New Phytol 2009, 183:62-75.

27. Voinnet $\mathrm{O}$, Rivas $\mathrm{S}$, Mestre $\mathrm{P}$, Baulcombe $\mathrm{D}$ : An enhanced transient expression system in plants based on suppression of gene silencing by the p19 protein of tomato bushy stunt virus. Plant J 2003, 33:949-956.

28. Walter M, Chaban C, Schütze K, Batistic O, Weckermann $K$, Näke $C$, Blazevic D, Grefe C, Schumacher K, Oecking C, Harter K, Kudla J: Visualization of protein interactions in living plant cells using bimolecular fluorescence complementation. Plant J 2004, 40:428-438.

29. Silverstone AL, Jung HS, Dill A, Kawaide H, Kamiya Y, Sun TP: Repressing a repressor: gibberellin-induced rapid reduction of the RGA protein in Arabidopsis. Plant Cell 2001, 13:1555-1566.

30. Clough SJ, Bent AF: Floral dip: a simplified method for Agrobacteriummediated transformation of Arabidopsis thaliana. Plant $J$ 1998, 16:735-743.

31. Orozco-Cardenas M, Ryan CA: Hydrogen peroxide is generated systemically in plant leaves by wounding and systemin via the octadecanoid pathway. Proc Natl Acad Sci USA 1999, 96:6553-6557.

doi:10.1186/1471-2199-12-22

Cite this article as: Shi et al: GhMPK16, a novel stress-responsive group D MAPK gene from cotton, is involved in disease resistance and drought sensitivity. BMC Molecular Biology 2011 12:22.

\section{Submit your next manuscript to BioMed Central and take full advantage of:}

- Convenient online submission

- Thorough peer review

- No space constraints or color figure charges

- Immediate publication on acceptance

- Inclusion in PubMed, CAS, Scopus and Google Scholar

- Research which is freely available for redistribution 